\title{
Didática desenvolvimental e as necessárias reelaborações dos currículos para o ensino de história*
}

\author{
Developmental didatics and the necessary redrawing of the curricula \\ for history teaching
}

Olavo Pereira Soares ${ }^{1}$

\begin{abstract}
RESUMO
$\mathrm{O}$ artigo tem por objetivo identificar as contribuições que os pressupostos teóricos e metodológicos da didática desenvolvimental nos fornecem para análise dos currículos para o ensino de história. Tais contribuições incidem tanto sobre a prescrição quanto ao praticado e nos encaminham para a necessária revisão das concepções sobre as aprendizagens presentes nas atuais propostas curriculares para o ensino da disciplina. Apresentamos dados que foram coletados em pesquisa-ação de caráter colaborativo realizada em escola pública. Tais dados demonstram que as atuais prescrições curriculares dificultam a efetivação de uma prática curricular que possibilite a pesquisa, a produção do conhecimento e o desenvolvimento do pensamento teórico por parte dos escolares. Não obstante, os mesmos dados nos possibilita propor modificações nos currículos praticados nas escolas.
\end{abstract}

Palavras-chave: Ensino de história. Currículo. Didática desenvolvimental. Aprendizagem conceitual.

\begin{abstract}
The article aims to identify the contributions that the theoretical and methodological assumptions of developmental didactics provide us to analyze the curricula for history teaching. These contributions focus both on prescription ando $\mathrm{n}$ what is practiced and lead us to the necessary revision of the conceptions about learning presented in the current curricular proposals for this discipline teaching. The data presented were collected in collaborative action research carried out in a public school. These data demonstrated that current curricular prescriptions make it difficult to put into effect a curricular practice that allows the research, production of knowledge and development of theoretical thinking by the scholars. Nevertheless, the same data allow us to propose modifications in the curricula practiced in schools.
\end{abstract}

Keywords: History teaching. Curriculum. Developmental didactics. Conceptual learning.

\footnotetext{
* A coleta de dados recebeu apoio financeiro da FAPEMIG através do Edital 12/2012.

1 Graduação em História Licenciatura pela UNESP/Assis, com Mestrado e Doutorado em Educação pela USP - Universidade de São Paulo. Pesquisa sobre ensino de história, didática, currículo e formação de professores. Atua nos cursos de graduação em História e Pedagogia da UNIFAL/MG e no PPGE - Programa de Pós-graduação em Educação da UNIFAL/MG. E-mail: olavopereirasoares@gmail.com.
} 


\section{Introdução}

Este artigo se une aos demais trabalhos sobre ensino de história que valorizam a inserção da pesquisa na elaboração do conhecimento histórico realizado em processos de educação escolar. Nosso objetivo é demonstrar a necessidade de revermos determinadas concepções sobre a aprendizagem e o desenvolvimento cognitivo que sustentam as propostas curriculares para o ensino da disciplina. Para tanto, nos referenciamos nos pressupostos teóricos e metodológicos da didática desenvolvimental, tanto para analisar as atuais propostas curriculares quanto para propor alternativas aos currículos prescritos e praticados.

Nas pesquisas sobre o ensino de história realizadas no Brasil esse referencial teórico é pouco utilizado, com exceção de pesquisas pontuais nas quais a categoria mediação é utilizada a partir de uma perspectiva vigotskiana. Em nossa concepção, os pressupostos teóricos e metodológicos da didática desenvolvimental têm muito a contribuir com as pesquisas no campo, notadamente nos seguintes aspectos: inserir nos debates sobre a temática as questões relacionadas ao desenvolvimento cognitivo; defender uma educação escolar e um ensino de história que sejam voltados aos processos mais amplos de valorização das capacidades humanas; referenciar pesquisas que pleiteiam a revisão das práticas escolares, em especial dos currículos e dos métodos de ensino.

Para apresentar nossos argumentos, dividimos esse artigo em dois momentos: no primeiro analisamos as relações entre o currículo prescrito, o currículo praticado e as concepções curriculares fundantes para o ensino da disciplina; posteriormente, a partir de dados de pesquisa realizada em escola pública e com o suporte teórico dos pressupostos da didática desenvolvimental, defenderemos um currículo que valorize o desenvolvimento do pensamento teórico nos alunos, bem como a necessária revisão das concepções sobre os currículos para o ensino de história. 


\section{0 currículo na escola: linearidade e naturalização do desenvolvimento}

Em pesquisa realizada em escola pública sobre processos de ensino e aprendizagem da história ${ }^{2}$ foi possível coletar dados sobre aspectos significativos do currículo e das práticas didáticas no ensino de história. A pesquisa se desenvolveu em uma escola pública da cidade de Alfenas, região sul do estado de Minas Gerais/Brasil. Ao longo dos anos de 2013 a 2016, uma professora de história da escola recebeu uma bolsa da Capes - Coordenação de Aperfeiçoamento do Pessoal de Ensino Superior - como incentivo para a participação na pesquisa. A pesquisa contou também com graduandos de iniciação científica do curso de história da UNIFAL-MG - Universidade Federal de Alfenas ${ }^{3}$.

Metodologicamente, no que tange a coleta e análise de dados, desenvolvemos uma pesquisa-ação de caráter colaborativo (PIMENTA, 2005; DESGAGNÉ, 2007). Inspirados em Zeichner (1998), a parceria com a escola pública e especificamente com a professora de história visava desenvolver atividades didáticas de ensino de história que tinham como objetivo melhoras qualitativas nas aprendizagens da história pelos alunos, considerando que para tal finalidade, seria necessário melhoras também qualitativas nos processos de apropriação e objetivação da leitura e da escrita pelos discentes (MELLO, 2010).

As reuniões de pesquisa realizadas na Universidade mesclavam estudos teóricos com a análise dos dados coletados na escola. Nas reuniões, nos detínhamos na análise das aprendizagens da história de uma turma específica, que no ano de 2013 estava no $5^{\circ}$ ano do ensino fundamental I, e em 2016, no $8^{\circ}$ ano do ensino fundamental II. Debruçamo-nos sobre os dados como pesquisadores e como professores de história, formados ou em formação. Coletivamente,

\footnotetext{
${ }^{2}$ Pesquisa intitulada "Leitura, escrita e interpretação da história com as crianças das escolas públicas", que contou com financiamento de um convênio entre a Fapemig - Fundação de Amparo a Pesquisa do Estado de Minas Gerais, e da Capes - Coordenação de Aperfeiçoamento do Pessoal de Ensino Superior.

3 A utilização dos dados relacionados às atividades didáticas realizadas na pesquisa foi devidamente aprovada pelo CEP/CONEP com Parecer de $\mathrm{n}^{\circ}$ 1.366.209, 14 de dezembro de 2015.
} 
elaborávamos atividades didáticas que objetivavam melhorias nas aprendizagens dos alunos.

A coleta de dados teve início com o acompanhamento das atividades didáticas dos alunos no processo de transição do $5^{\circ}$ para $6^{\circ}$ ano do ensino fundamental, considerando que esse é o momento em que ocorrem modificações didáticas mais significativas na trajetória do estudante: o fim do vínculo afetivo com o professor polivalente, a dificuldade em lidar com a diversidade de professores e disciplinas específicas, a maior cobrança por autonomia em relação às atividades escolares. Neste contexto, nos propusemos a organizar atividades de ensino de história que auxiliassem os alunos na transição do ensino fundamental I para o fundamental II.

Ao iniciarmos as atividades no momento em que a turma ingressou no $6^{\circ}$ ano, nós constatamos a dificuldade da professora em promover alterações no currículo prescrito. Havia diferentes níveis de dificuldades: às de ordem pragmática, pois seguir o currículo prescrito poderia significar melhores notas nas avaliações sistêmicas e com isso melhorias no salário; às de ordem prática, pois os livros didáticos aprovados no PNLD - Programa Nacional do Livro Didático - continham diferenças de conteúdo e de cronologia em relação ao currículo prescrito do Estado de Minas Gerais (CBC/SEE-MG; 2011).

A solução que nos parecia óbvia, destarte as preocupações iniciais da professora e da gestão escolar, era adequar o currículo prescrito ao praticado. Selecionar temas e conteúdos que eram solicitados na prescrição curricular, mas que encontravam respaldo no material didático indicado no PNLD e disponibilizado na escola. Tentamos com isso suprir as dificuldades de ordem pragmática e prática.

Ao utilizar algumas temáticas da prescrição, nossas atividades mantinham os alunos no interior do currículo prescrito e, portanto, das avaliações sistêmicas que tanto preocupam os professores e a gestão escolar. Manter a utilização do livro didático como um importante recurso também era importante, pois a carência financeira da maioria dos alunos da escola fazia com que o livro fosse, 
em muitas situações, a única fonte de acesso dos alunos e seus familiares ao conhecimento histórico.

Foi no contexto de adaptação do currículo prescrito ao praticado que passamos a nos interessar pela análise dos paradigmas nos quais se assentam a prescrição, bem como identificar a possibilidade de superar tais paradigmas com o intuito de buscar uma relação mais harmoniosa entre a prescrição e a prática escolar.

Durante os anos da pesquisa, os currículos para o ensino de história em Minas Gerais estavam definidos nos documentos do CBC - Conteúdos Básicos Comuns, da SEE/MG - Secretaria Estadual de Educação de Minas Gerais (CBC/SEE-MG, 2011). Nesse currículo, fica explicita a concepção de que as aprendizagens sobre outros tempos e espaços ocorrem de forma linear e cumulativa, do mais próximo ao mais distante. Concepção que havia sido parcialmente rompida com a publicação dos PCN's - Parâmetros Curriculares Nacionais (BRASIL, 1998) da área de História, mas que foi retomada com afinco pela atual BNCC - Base Nacional Curricular Comum (BRASIL, 2017).

O que verificamos é que no Brasil existe uma tradição nas formulações de currículos para o ensino de história que incorporam os princípios paradigmáticos piagetianos. Ao considerar os estágios do desenvolvimento propostos por Piaget (1998; 2012), as crianças que frequentam o ensino fundamental I devem ter contato com conteúdos que são próximos, no tempo e no espaço, como a história da família em suas relações com a história da rua, do bairro e da cidade. Assim, o currículo acompanha o avanço da idade biológica dos estudantes, pois ao estarem próximos do ingresso no ensino fundamental II eles podem estudar outros tempos e espaços, mas sempre de forma linear e cumulativa.

Implícito a essas propostas curriculares há duas concepções sobre a aprendizagem da história escolar: de que o conhecimento de uma determinada temporalidade deve após os estudantes atingirem determinadas etapas do desenvolvimento, ou seja, de que é preciso esperar a maturação das crianças e adolescentes para estudo de um conhecimento mais complexo sobre o passado; de 
que a noção de passado está relacionada unicamente às formas de conhecimento escolar.

A prescrição curricular de Minas Gerais mantém essas concepções. O primeiro eixo temático da prescrição voltado para o $6^{\circ}$ ano do ensino fundamental II tem o seguinte título: "Histórias de vida, diversidade populacional e migrações" (CBC/SEE-MG; 2011, p. 22). Nos tópicos que compõem esse eixo temático, há um esforço da prescrição em inserir os alunos na compreensão da temporalidade. Assim, parte do estudo da população mineira e sua diversidade na atualidade, ou seja, naquilo que é próximo no tempo e no espaço. Em seguida, vem o estudo das origens da população de Minas Gerais: os povos indígenas, os africanos e os europeus que ocuparam o território em diferentes temporalidades; em suma, estuda o mesmo espaço em tempos diversos. Nos demais eixos temáticos, tema e subtemas da prescrição, o currículo assume a postura de um currículo em espiral: na medida em que avançam os anos de escolarização, é permitido aos alunos outros tempos e espaços mais distantes.

No que se refere à aprendizagem da história, não há respaldo teórico da historiografia para tais formulações curriculares. Ficamos então, com algumas perguntas: como se criou esse senso comum, quase uma vulgata, em torno dos pressupostos piagetianos? Por que a maioria das prescrições e dos livros didáticos ainda mantém a linearidade e a cronologia?

Ao analisar as relações entre o currículo prescrito e o praticado e considerando que o praticado exige procedimentos didáticos, outras questões precisam ser analisadas, por exemplo: por que o estudo de certas tradições culturais brasileiras prescinde da aprendizagem de aspectos históricos da Idade Média europeia? Por que a curiosidade dos alunos sobre as relações entre evolução biológica e formação das primeiras sociedades deve se restringir ao primeiro ano do ensino fundamental II? Por que a análise das grandes guerras do século XX e dos modelos políticos e econômicos em disputa precisa ser privilégio apenas dos alunos do $9^{\circ}$ ano ou do ensino médio? Em que medida essa estrutura dificulta o desenvolvimento de um pensamento teórico sobre o passado? 
É certo que no cotidiano escolar, as concepções de um currículo linear, cumulativo ou em espiral dificultam práticas de ensino de história que sejam voltadas para a produção do conhecimento, pois impõe uma concepção de aprendizagem que considera o aluno uma tábula rasa, sem vínculos com as diferentes dimensões da história. Para promover um ensino de história que possibilite a máxima valorização humana dos alunos e professores (Libâneo; 2012), é preciso rever tais concep̧̧ões.

Uma análise dos postulados piagetianos possibilitam outros paradigmas para as pesquisas sobre as relações entre ensino de história e desenvolvimento humano. Nos postulados piagetianos, o ensino deve estar a reboque do desenvolvimento, ou seja, o ensino de um determinado conteúdo ou conceito deve ocorrer quando se percebe o "amadurecimento" da criança ou do adolescente em relação aquilo que deve ser ensinado. Para nós, que compartilhamos da perspectiva vigotskiana, deve ocorrer o oposto: o ensino deve se adiantar e alavancar o desenvolvimento (Vigotski, 2001). Isto ocorre quando os processos curriculares e as atividades didáticas possibilitam aos alunos um conhecimento novo e que exige deles novas capacidades cognitivas.

As concepções de que o desenvolvimento cognitivo da criança está à deriva ou à "mercê" do desenvolvimento biológico e de que o "social age através da coação", tiveram grande impacto nas teorias educacionais do século XX, sendo reavivado nos anos 1990 com as pedagogias das competências e habilidades (Duarte, 2001). Ainda hoje, é possível verificar nas escolas a força das concepções biologizantes e pragmáticas, em especial quando se trata de explicar as aprendizagens dos alunos.

A concepção piagetiana na qual "o biológico é concebido como primário, fundante" (Vigotski; 2001, p.79) está, segundo Vigotski, intimamente vinculada ao método de pesquisa implementado por Piaget, e que também influenciaram significativamente as pesquisas sobre a didática. É na análise do método piagetiano que se explicita a concepção de que as crianças têm características que são universais e que seu desenvolvimento é biologicamente determinado. $\mathrm{Na}$ crítica ao método, Vigotski faz a seguinte ponderação: 
Neste caso, o fundamental são a ausência de realidade e a relação da criança com essa realidade, isto é, a ausência de atividade prática da criança. Piaget examina a própria socialização do pensamento da criança fora da prática, dissociada da realidade, como comunicação pura de almas que leva ao desenvolvimento do pensamento. (VIGOTSKI, 2001, p. 79).

O trabalho de Piaget sobre o ensino de história (Piaget, 1998) explicita, com clareza, a crítica vigotskiana, tanto do ponto de vista teórico quanto metodológico.

No início dos anos 1930, Piaget foi instigado a pesquisar sobre a eficácia do ensino de história nos primeiros anos de escolarização, bem como propor soluções para as dificuldades apresentadas no ensino da disciplina (PIAGET, 1998). Piaget aceitou o desafio, e se utilizou de seus princípios teóricos e metodológicos para coletar dados para a pesquisa solicitada. Tais princípios nos dizem muito sobre os referenciais piagetianos.

O método da pesquisa implementada por Piaget foi identificado por ele mesmo como "método clínico", que consiste, basicamente, em substituir a metodologia do questionário ou do "interrogatório flexível” por uma "conversa livre" (Piaget; 1998, p.90). Essa conversa com o pesquisador e a criança não ocorre em ambiente da sala de aula, tampouco escolar, pois o objetivo é identificar as "atitudes intelectuais espontâneas da criança" (PIAGET, 1998, p.95).

A equipe liderada por Piaget tinha três objetivos principais: analisar a noção que a criança tem do passado; se existem, nas crianças, representações espontâneas relativas à história da civilização; se as crianças identificam os conhecimentos históricos como sendo específicos de seu grupo social ou se podem ser generalizados (PIAGET, 1998, p.90-91). A partir desses objetivos gerais, foram realizadas conversas com as crianças para a coleta de dados.

As conversas realizadas com as crianças giravam em torno de perguntas sobre aspectos da história da cidade de Genebra e da Suíça. Assim, conversaram sobre elementos da cultura material do passado, sobre o cotidiano, sobre fatos e personagens históricos marcantes da história genebrina, ou seja, daquilo que era historicamente significativo para os genebrinos no entre guerras. 
É imperioso destacar que a pesquisa coordenada por Piaget já partia do seguinte pressuposto:

A compreensão da história supõe a noção do tempo, sob o duplo aspecto da avaliação da duração e da seriação dos acontecimentos. Contudo, tudo o que sabemos atualmente sobre a memória da criança mostra que, mesmo no terreno do tempo individual, a duração é mal mensurada e as lembranças não são corretamente ordenadas. Com mais razão ainda, o mesmo deve ocorrer no que concerne ao passado não vivido. (PIAGET, 1998, p.91, grifo do autor).

Já estava pressuposto ao pesquisador que as crianças não tinham condições de aprender história, pois a história ensinada na escola requer a compreensão da noção de tempo, no que tange a compreensão da duração e da seriação dos acontecimentos. Assim, estava pressuposto também que as conversas para coletar dados apenas ocorreram para comprovar a tese já apresentada. Tinham como pressuposto inicial que a noção de tempo deve estar "amadurecida" na criança para que ela possa aprender história, e, por conseguinte, que a ausência da noção de tempo inibe o aprendizado de uma história que venha exigir dela deslocamentos temporais e espaciais.

As conclusões de Piaget são emblemáticas e, como sabemos, influenciaram as pesquisas sobre o ensino de história, bem como as políticas curriculares de muitos países durante todo o século XX.

Para Piaget, o passado é para a criança apenas um decalque do presente: “O passado infantil não é nem distante, nem ordenado em épocas distintas. Ele não é qualitativamente diferente do presente. A humanidade permanece idêntica a si própria, tanto na sua civilização quanto nas suas atitudes morais" (PIAGET, 1998, p.95). Essa conclusão de Piaget deriva do fato de que as crianças percebiam no passado uma extensão do presente, ou seja, os objetos pessoais, os meios de transporte, as relações sociais já existiam no passado, mas em formato inferior, embrionário.

Outra conclusão significativa de Piaget se refere ao fato de que tais atitudes das crianças, em relação ao conhecimento histórico, estão vinculadas a uma variante do pensamento egocêntrico: "É possível que um tal egocentrismo 
tenha apenas pouca importância no ensino da história. Mas, no fundo, não será essa atitude que explica a irracionalidade e a parcialidade dos julgamentos de valor?" (PIAGET, 1998, p.94, grifo do autor).

As teorias de Piaget sobre o desenvolvimento infantil procuram demonstrar que o ingresso das crianças no processo de escolarização coincide com o abandono do pensamento egocêntrico. No entanto, para a aprendizagem da história, Piaget considera que subsiste na criança os resquícios de "um tal egocentrismo" que dificulta o seu aprendizado sobre o passado. Explica-se assim a dificuldade que a criança tem em separar o passado do presente, bem como em identificar as especificidades do passado, tanto do seu grupo social quanto de outros povos.

As sugestões apresentadas por Piaget para a superação de tais dificuldades encontradas no ensino da história são emblemáticas:

...a educação do senso histórico da criança pressupõe a do espírito crítico ou objetivo, a da reciprocidade intelectual e a do senso das relações ou das escalas, nada parece mais apropriado para determinar a técnica do ensino da História do que um estudo psicológico das atitudes intelectuais espontâneas da criança, por mais ingênuas e insignificantes que possam parecer à primeira vista. (PIAGET, 1998, p. 95, grifo do autor).

O que nos chama atenção na assertiva piagetiana é o que ele considera como "atitudes intelectuais espontâneas das crianças". Trata-se de uma concepção segundo a qual a criança tem um pensamento que lhe é próprio, que tem significados específicos. Assim, o que é "espontâneo" não se difere substancialmente do "egocêntrico" visto que o importante é identificar as dificuldades que a criança tem de aprender sobre o passado. O ensino de história para as crianças deveria ter como objetivo preparar para desvincular a criança de seu egocentrismo primitivo, daí decorre a necessidade de desenvolver na criança o "senso das relações ou das escalas".

Para nós, referenciados na teoria histórico-cultural, trata-se fundamentalmente de diferenças no plano teórico e metodológico de abordagem 
da temática. Nosso referencial nos permite levantar outras hipóteses para as mesmas questões.

Sabemos, por exemplo, que não existem "atitudes intelectuais espontâneas". As formas de pensar e agir não se dissociam do processo histórico e do contexto social ao qual estamos inseridos (VIGOTSKI, 2001, 2011). Piaget, ao fazer perguntas sobre as aprendizagens das crianças suíças, inferiu que as crianças de diferentes regiões e sociedades têm as mesmas facilidades e dificuldades de aprendizagem.

Temos aqui, uma primeira divergência de cunho metodológico. O método clínico utilizado por Piaget e sua equipe isolava a criança de seu contexto social. Este isolamento pode ser percebido porque as conversas eram realizadas em um contexto estranho à criança, fora do ambiente escolar e social, sem a presença de outras crianças ou parentes próximos, bem como no fato de que, nas conversas, as crianças eram submetidas a perguntas que claramente não saberiam responder. Esperava-se assim identificar as "atitudes intelectuais espontâneas" das crianças, atitudes puras, sem as intervenções dos processos de ensino.

Sem contato com outras crianças ou familiares para dialogar sobre assuntos complexos, a criança era inserida em um monólogo, no qual não há mediações, diálogos sobre diferentes experiências, levantamento de hipóteses.

No relato apresentado por Piaget (1998), ele descreve que as crianças conheciam bem sobre alguns personagens e fatos da história de Genebra e da Suíça. Ocorre que não explicita se havia a inserção desses conteúdos no currículo escolar. Subentende-se que as crianças tinham esses conhecimentos, pois esses faziam parte das festividades coletivas, de cunho nacionalista e patriótico. Nas conversas para a coleta de dados, as crianças, em idades de 7 a 11 anos, conversavam com os adultos sobre fatos e personagens que variavam no tempo, dos povos lacustres (pré-românicos) aos eventos políticos dos séculos XIV e XVII.

Piaget e sua equipe esperavam que uma criança de sete anos tivesse uma noção de temporalidade e de linearidade que só é possível com a aprendizagem 
escolar. Além disso, trata da "noção de tempo" na criança como algo inato, como se fosse uma etapa da sua maturação cognitiva. Ocorre que a aprendizagem da "noção de tempo" a qual Piaget se referia, está vinculada a um tipo específico de aprendizagem, que é a aprendizagem elaborada a partir da produção do conhecimento histórico escolar.

Como a pesquisa já partia do pressuposto de que "a compreensão da história supõe a noção do tempo, sob o duplo aspecto da avaliação da duração e da seriação dos acontecimentos". (PIAGET, 1998, p.91, grifo do autor), as perguntas estavam pré-definidas para comprovar a tese inicial, qual seja: as crianças, dos anos iniciais da escolarização não têm condições cognitivas de aprender história.

No Brasil, algumas pesquisas que se utilizam do referencial piagetiano chegaram a conclusões semelhantes. A pesquisa de Sandra Oliveira (2003) se utilizou do mesmo "método clínico" para a coleta de dados, inclusive com perguntas semelhantes àquelas feitas por Piaget, apenas com adaptações ao contexto brasileiro. Não é de se estranhar que as conclusões fossem as mesmas do pesquisador suíço:

No que se refere à noção de passado, percebemos que a criança analisa os acontecimentos através da sua lógica operatória. Ela não é capaz de relacionar a duração de vida do seu pai, avô ou bisavô com a ideia de sucessão no tempo. As crianças com sete anos concluem, com frequência, que seu bisavô estava vivo na época do descobrimento do Brasil por que ele é muito velho. (OLIVEIRA, 2003, p. 168).

Assim como em Piaget, a pesquisa de Oliveira (2003) não argumenta sobre quais aspectos da vida da criança são preponderantes para que elas tenham uma "noção sobre o passado". O desenvolvimento cognitivo da criança de sete anos já estaria definido pela sua "lógica operatória". Assim, são as fases de desenvolvimento da criança, identificadas nas pesquisas de Piaget, que definem as capacidades cognitivas das crianças aprenderem história. 
Não por acaso, a pesquisa de Oliveira (2003) irá defender que o ensino de história para crianças deva superar a concepção de que a cronologia é algo determinante para o aprendizado da história. Segundo Oliveira (2003), isto é necessário porque as crianças desenvolvem uma noção de passado em que "o tempo histórico é uma construção causal e não meramente cronológica" (OLIVEIRA, 2003, p. 168), visto que, nas diferentes conversas sobre o passado, a maioria das crianças negligenciaram a cronologia em função de explicações sobre o passado baseados em causa e efeito. Novamente, verificamos que se explicita o que as crianças não aprendem, nesse caso, a cronologia. Mas é preciso tentar explicar como e porque as crianças desenvolveram a noção de causalidade dos processos históricos. Concordamos com Oliveira (2003) que a noção de tempo cronológico não é fundamental para aprendizagem da história. Não obstante, é preciso considerar que a noção de causalidade também não é algo espontâneo.

Imaginemos, por exemplo, a relação das crianças com a religião e a religiosidade, e como isto pode afetar as suas noções sobre o passado. Crianças que frequentam instituições religiosas adquirem noções sobre o tempo histórico que se diferenciam, tanto daquelas crianças que não são assíduas a nenhuma religião, quanto das crianças que frequentam instituições religiosas diferentes. Podemos inferir também que as noções sobre temporalidade, espacialidade, transformações e permanências, são funções psíquicas superiores que se desenvolvem em estreita relação das crianças e adolescentes com o seu contexto social. Em outras palavras: não existe no desenvolvimento cognitivo a elaboração de um pensamento espontâneo sobre o passado. As noções que as crianças desenvolvem sobre o passado, sobre as temporalidades e também sobre a cronologia estão vinculadas com suas vivências, com as relações que estabelecem com o meio (VIGOTSKI, 2010).

O princípio de que é na relação da criança com o meio que encontramos os elementos fundamentais para compreender o desenvolvimento cognitivo (VIGOTSKI, 2010), nos leva a refutar a tese piagetiana de que a criança percebe e compreende a história de forma espontânea, como se o passado refletisse o 
presente. A própria construção da história por adultos é, em grande medida, um reflexo do presente. Desde o século XIX, as festas nacionalistas que se apoiam em fatos históricos impõem ao passado valores e conceitos do seu tempo, e esse é um processo comum a muitas sociedades. Exemplos mais recentes estão em diversas mídias: desenhos infantis, filmes para adolescentes e adultos, games e uma extensa literatura de ficção se utilizam da história para contextualizar seus personagens. Nas mídias, a história é apenas um "pano de fundo" para um enredo sobre questões do tempo presente, é a própria extensão do presente.

Não há como considerar que o pensamento da criança sobre o passado seja espontâneo. Inseridas em sociedades, crianças e adolescentes vivenciam, conhecem e interagem com o passado que é comum àquele grupo social. Portanto, é preciso considerar que a criança está inserida em um contexto histórico e social, ou seja, ela aprende história em casa e em sua vida cotidiana.

Considerando esse debate é possível afirmar que não há base científica de cunho psicológico que justifique a elaboração de currículos para o ensino de história que sejam lineares e cronológicos, que se iniciem do mais simples ao mais complexo ou que se trilhem o caminho do modelo em "espiral" que vai do conhecimento mais próximo no tempo e no espaço, ao mais distante. Tais currículos estão mais baseados em uma tradição disciplinar do que em concepções teóricas bem definidas.

As revisões nas concepções sobre o currículo para o ensino de história devem considerar algumas premissas: que a aprendizagem da história, enquanto conhecimento produzido depende sobremaneira dos processos de educação escolar; que não há maturação biológica que justifique uma relação linear e cumulativa entre conhecimentos mais ou menos complexos; que a complexidade dos conhecimentos abordados depende dos aspectos sociais, históricos e culturais aos quais os alunos estão inseridos; que a atividade didática elaborada pelos professores é que podem definir o nível de complexidade, de apreensão e de produção do conhecimento histórico por parte dos alunos. 


\section{Adaptar o prescrito, modificar o praticado e desenvolver o humano}

Em nossas pesquisas, as possibilidades de modificação na estrutura curricular estão referenciadas na obra de V. V. Davidov, pesquisador da terceira geração de soviéticos vinculados à perspectiva histórico-cultural. Parte significativa da obra de Davidov (DAVIDOV, 1982, 1988) teve por objetivo demonstrar que a maioria das concepções curriculares assumidas pelas escolas não possibilitam aos alunos o desenvolvimento de um pensamento teórico sobre a realidade.

Segundo Davidov, o currículo escolar apresenta a seguinte contradição: os conhecimentos transmitidos aos alunos são resultado da produção científica, porém as práticas de ensino não permitem aos alunos o desenvolvimento do pensamento teórico-científico acerca desses conhecimentos. Isso ocorre porque na maioria das situações os alunos entram em contato com o objeto do conhecimento a partir do resultado do conhecimento produzido e de sua representação já definida pela ciência (DAVIDOV, 1982). Não se disponibiliza aos alunos o processo de elaboração do conhecimento, os métodos empregados e as perguntas formuladas pelos cientistas.

$\mathrm{Na}$ produção historiográfica, quando os historiadores se debruçam sobre uma determinada temática, eles precisam inicialmente definir sobre qual perspectiva teórica a temática será analisada. Concomitante ou posterior a esse processo serão definidas as fontes para a pesquisa, os dados e as hipóteses a serem levantadas. Ao historiador cabe uma profusão de perguntas e o convívio com as contradições é algo inerente ao exercício da pesquisa e a busca por resultados. No entanto, ao chegar à escola, este conhecimento "produzido" pelo historiador não permite aos alunos a mesma trajetória intelectual. Em outras palavras: os alunos tem acesso às descobertas do historiador, mas não é instigado a desenvolver as mesmas formas de pensamento. 
Os atuais currículos pressupõem que ao se relacionarem de modo perceptivo e sensorial com os objetos em determinadas etapas da escolarização, os alunos irão desenvolver naturalmente as capacidades mais complexas de apreensão dos conhecimentos que exigem maior abstração. Os currículos de história partem do princípio que após estudar sobre a sua cidade e região, bem como ter noções sobre cidadania, os alunos irão aprender com mais facilidade o conceito de Estado, que é mais abstrato e abrangente. Ocorre que "o esquema de 'baixo para cima' não garante o movimento 'de cima para baixo', o trânsito do geral ao particular" (DAVIDOV; 1982, p. 29, tradução nossa). Ou seja, a aprendizagem do conceito de Estado não ocorrerá se não houver propostas didáticas que possibilitem aos alunos essa abstração.

Parte-se do pressuposto que a aprendizagem dos conceitos históricos se dá a partir de generalizações dos atributos externos e sensíveis sobre o conhecimento apresentado. A escravidão, por exemplo, é estudada a partir de atributos sensoriais, tais como o sofrimento e a dor, mas não do que define historicamente o escravo e a escravidão (DAVIDOV, 1982). Em suma: aprende-se sobre a aparência do objeto, mas não se estuda a essência do conceito e do objeto a ser analisado. Segundo Davidov, esse movimento de ensinar a partir do que é sensorial e perceptível, notadamente através da observação, não possibilita aos alunos o desenvolvimento do pensamento teórico e abstrato, ainda que esse seja um dos objetivos explícitos da prescrição.

Quando os atributos externos são evidenciados no ensino de história, os estudantes não acessam as peculiaridades relacionadas à produção do conhecimento histórico. Decorrem deste aspecto as explicações empiristas, anacrônicas e subjetivistas da história, como se todo processo histórico fosse dotado dos mesmos elementos: luta, dor, superação ou patriotismo.

Nosso contato com o currículo prescrito na pesquisa desenvolvida na escola demonstrou o quanto ainda estamos vinculados a propostas curriculares descritivas, que se convertem nas práticas em processos de aprendizagem destinados ao desenvolvimento do pensamento empírico e de senso-comum. 
$\mathrm{Na}$ pesquisa em análise, um dos tópicos da prescrição para o $7^{\circ}$ ano tem a seguinte definição: "bases do estado monárquico e limites da cidadania: patrimonialismo, escravidão e grande propriedade"; o primeiro subitem solicita a "habilidade" de "analisar e compreender as bases socioeconômicas da monarquia brasileira, identificando continuidades e mudanças em relação à era colonial e à época atual", para que, no segundo subitem a "habilidade" solicitada seja "conceituar patrimonialismo e estado" (CBC/SEE-MG, 2011, p. 26). Ou seja, a aprendizagem do conceito não é o tópico principal, é um subitem que está atrelado às características do objeto em um determinado tempo e espaço que são específicos: o Estado no Brasil monárquico. Essa abordagem dificulta a abstração, pois propõe aos professores e alunos que o conceito pode ser apreendido, mas a partir das características definidas previamente, neste caso, o Estado na monarquia e suas especificidades.

Nossas pesquisas nos encaminham para uma abordagem do currículo que possibilite aos alunos o desenvolvimento do pensamento teórico e das capacidades cognitivas mais elevadas. Tal abordagem deve ter como princípio a aprendizagem de conceitos (DAVIDOV, 1982). A aprendizagem conceitual proposta por Davidov (DAVIDOV, 1982, 1988) parte do pressuposto de que o conceito deve ser analisado na sua essência, nas suas características intrínsecas e que o movimento pedagógico de aprendizagem conceitual deve partir do abstrato para o concreto, e não o seu oposto.

Isso não significa que o tanto o pensamento prático quanto o conhecimento empírico devem ser alijados da prática curricular. O que se espera é que se explicitem para professores e alunos as funções sociais das diferentes formas de conhecimento, bem como das relações que as diferentes formas de pensamento estabelecem com o desenvolvimento cognitivo. Tanto o currículo prescrito quanto o praticado devem considerar os diferentes contextos históricos e sociais aos quais os alunos estão inseridos, haja vista que as relações destes com o conhecimento histórico também são específicas. Não podemos desconsiderar que a religiosidade, a classe social, o uso de bens materiais, o acesso a serviços públicos, o contato com 
as mídias e a formação cultural dos familiares, constituem-se em aspectos da vida social que possibilitam determinadas visões sobre o passado e um conhecimento empírico sobre a história.

Para que possa ocorrer uma aprendizagem conceitual no ensino de história é preciso inverter a lógica das atuais prescrições: valorizar primeiro as abstrações e o pensamento teórico e, posteriormente, elucidar as perguntas dos alunos com os resultados da pesquisa historiográfica.

Retomando o exemplo já apresentado: os estudantes, com o auxílio do professor deveriam elaborar uma definição sobre o conceito de Estado para, posteriormente, os alunos terem acesso às características que a historiografia apresenta do Estado monárquico.

Ao longo da pesquisa fizemos alguns ensaios que nos permitem indicar a viabilidade dessa inversão na lógica curricular. Trata-se de ensaios, pois como já afirmamos a pesquisa não poderia transgredir ou subverter o currículo prescrito. Sendo pesquisa em colaboração, tínhamos que atender também as demandas da escola e dos professores, considerando que a adequação da prescrição era uma necessidade prática e pragmática imposta ao cotidiano escolar.

A título de síntese, apresentamos a seguir como foi desenvolvido o trabalho didático com o conceito de "evolução" que ocorreu quando a turma estava no $6^{\circ}$ ano.

O objetivo da atividade era fazer um recorte conceitual a partir dos diversos conteúdos indicados na prescrição, a saber: "caracterizar e diferenciar os povoadores de origem asiática (mongolóides) e de origem africana (negróides) e confrontar interpretações distintas sobre sua identidade", para posteriormente "problematizar a distinção entre história e pré-história" e, ao final, "caracterizar e analisar a origem, evolução e diversidade da espécie humana” (CBC/SEE-MG; 2011, p. 22).

Novamente é possível verificar como a prescrição dificulta o desenvolvimento de atividades didáticas que visam o melhor desenvolvimento 
cognitivo dos alunos. Apesar de a prescrição solicitar o estudo de tempos diversos, ela mantém a linearidade e a concepção de que os alunos aprendem a partir do que é concreto. Isto fica evidente não apenas pelo uso dos verbos "caracterizar $e$ diferenciar", mas pela concepção de que o conteúdo que exige maior abstração deve ser posterior àquele mais perceptível.

$\mathrm{Na}$ pesquisa resolvemos inverter essa lógica curricular e possibilitar aos alunos primeiro o estudo do conceito de evolução e, posteriormente as características dos diversos fenótipos presentes na sociedade mineira, que é o objetivo implícito à prescrição. Assim, objetivamos contribuir com o desenvolvimento cognitivo dos alunos através de atividades que valorizassem o pensamento abstrato (DAVIDOV, 1988).

Quando teve início as atividades didáticas sobre o conceito evolução, fizemos um levantamento inicial dos conhecimentos prévios dos alunos e de como eles se relacionam com a temática. Isso é importante, pois ao mesmo tempo de apresenta as particularidades do desenvolvimento dos alunos, possibilita identificar os níveis de apropriação do conhecimento da turma em relação aos conteúdos a serem analisados. Isso é importante por que:

O desenvolvimento de cada criança ocorre de forma singular, no entanto, há traços comuns entre estudantes de uma mesma sala de aula, seja porque participaram de situações sociais de desenvolvimento semelhantes, seja porque frequentaram a mesma sala de aula, a mesma escola, seja ainda porque participaram ou participam da mesma comunidade. Enfim, os estudantes de uma sala estão envoltos em uma mesma cultura na escola e na comunidade e partilham um histórico semelhante (SFORNI, 2015, p. 383).

Nesse levantamento inicial percebemos que havia algumas resistências da turma em relação a esse estudo. Provavelmente, tais resistências estivessem relacionadas com a religiosidade dos alunos e familiares, o que nos leva a supor que havia um conhecimento cotidiano da turma sobre o conceito, ou seja, o conceito de evolução era percebido de forma pejorativa pelos alunos e eles evitariam participar do processo de produção sobre esse conhecimento. Tínhamos, 
portanto, a necessidade de possibilitar aos alunos uma empatia com o objeto de estudo (DAVIDOV, 1988).

Retomamos então com a temática do criacionismo, buscando incentivar os estudantes a utilizar esse conhecimento para interpretar outras culturas, em outros tempos e espaços. Assim, propusemos a leitura de textos sobre "mitos de origem" de diferentes religiões e grupos sociais: cristãos, hinduístas, gregos, índios brasileiros e povos africanos. Os alunos se dividiram em pequenos grupos, leram e conversaram sobre os mitos, bem como explicaram para os demais grupos da sala sobre o que tinham lido.

Após a leitura e interpretação dos mitos, cada grupo recebeu uma cartolina com a seguinte comanda: representar através de um desenho a interpretação que o grupo fez do mito. Depois, apresentaram para a turma o desenho e a interpretação que tiveram. Assim, os alunos ingressaram no estudo do conceito de evolução através de uma atividade que lhes propiciou o pensamento teórico e abstrato sobre um objeto correlato, que são os mitos de origem. O criacionismo, enquanto conhecimento cotidiano, não foi analisado como sendo a negação da ciência e das teorias da evolução, mas foram percebidos como uma característica que demonstra o "geral" e o "particular" que existe em diferentes grupos sociais, em tempos e espaços diversos (SILVA, 1995).

A leitura e os desenhos sobre os mitos de origem desenvolveu uma empatia com a temática e possibilitou aos alunos uma pergunta teórica e abstrata mais ampla e complexa: afinal, de onde viemos e quais são as origens da humanidade?

Retomamos então, os objetivos da prescrição que é aprendizagem sobre a "origem, evolução e diversidade da espécie humana” (CBC/SEE-MG; 2011, p. 22). Porém, invertendo a lógica definida no currículo. Nas aulas seguintes, a turma estava mais predisposta a debater sobre as teorias da evolução, bem como sobre as hipóteses que o livro didático apresentava para o povoamento do continente americano. 
A teoria da evolução, bem como o próprio conceito de evolução foi pensando inicialmente de forma teórica e abstrata, como uma explicação científica para a mesma pergunta elaborada pelos alunos. Assim, com mais empatia e mais predisposição para a temática, os alunos puderam participar da formulação do conceito, analisar como os cientistas elaboram e trabalham com o conceito. Após a elaboração teórica, é que os alunos interagiram com as características e diferenciações propostas pela prescrição (CBC/SEE-MG; 2011, p. 22).

Tal experiência demonstra que práticas didáticas voltadas para o desenvolvimento do pensamento teórico e abstrato não são apenas possíveis, mas necessárias. Ao tentarem entender sobre a essência do conceito de evolução, os alunos elaboraram hipóteses que os aproximaram de um conhecimento mais abrangente sobre a mesma temática. Portanto, um ensino de história que valorize o desenvolvimento humano deve subverter a lógica curricular existente, possibilitando aos alunos não apenas as ferramentas práticas do ofício do historiador, mas também as ferramentas teóricas que transformam o fazer historiográfico em algo fascinante: as perguntas, as hipóteses, as dúvidas, as contradições.

\section{Considerações finais}

Neste texto, analisamos as bases teóricas para a defesa de um ensino de história voltado para a promoção integral do aluno como ser humano: a capacidade de se inserir no processo histórico da humanidade e desnaturalizar a vida cotidiana, de produzir conhecimento e através dele desenvolver-se cognitivamente, de referenciar-se no passado como ferramenta do pensamento, de compreender-se como produtor e não apenas consumidor de cultura. Trata-se de valorizar o ensino desta disciplina escolar naquilo que definimos como sendo uma perspectiva humana e humanizadora.

Nossas intenções se aproximam de outros trabalhos sobre o ensino de história ao defendermos que a produção do conhecimento histórico escolar deve 
aproximar os alunos dos métodos da pesquisa histórica utilizados pelos historiadores. Acreditamos que o aprendizado de aspectos básicos da pesquisa histórica é fundamental porque desnaturaliza a própria produção da história. No entanto, acrescentamos que além desse aspecto, a produção do conhecimento histórico escolar deve aproximar os alunos de um tipo de conhecimento que é específico da produção científica: o conhecimento teórico.

Ocorre que para desenvolver a contento a pesquisa e o conhecimento científico em âmbito escolar é preciso possibilitar aos alunos a elaboração do pensamento teórico, que se distingue sobremaneira do pensamento empírico. Para que esse movimento se concretize, ou seja, o desenvolvimento do pensamento teórico que possibilita a produção da pesquisa e do conhecimento teórico do objeto do conhecimento histórico, faz-se necessário uma revisão paradigmática nos currículos e nas didáticas da disciplina.

Por esta razão, nós divergimos dos postulados piagetianos e das demais concepções que defendem que o currículo deve partir do conhecimento mais simples para o mais complexo, de modo linear e cumulativo.

Defendemos aqui um ensino de história voltado para o desenvolvimento humano, um ensino que valorize o aluno como produtor de conhecimento, um conhecimento que é universal e não apenas significativo para a turma, a escola ou localidade. Um bom ensino de história deve situar os estudantes na história da humanidade, em complexidade que, esta sim, seja variável em função da turma, da escola, da localidade.

Ademais, o que aprendemos com os autores fundantes da teoria históricocultural, é que o ensino escolar deve ser sempre desenvolvente, no sentido de possibilitar o humano que há em cada criança. Assumindo tais assertivas, o ensino de história na escola, passa a ser um ensino que une conflito e satisfação: descobrir que as trajetórias pessoais e coletivas não são nem nunca foram naturais geram conflitos, mas identificar possibilidades de mudanças e de transformações da realidade traz enorme satisfação. 
$\mathrm{O}$ que nos leva à necessidade de pesquisar sobre as metodologias de ensino, mas isso é outra história.

\section{Referências}

BRASIL. Parâmetros Curriculares Nacionais/História. Brasília: MEC/SEF, 1998.

BRASIL. Base Nacional Comum Curricular. Brasília: MEC/SEB, 2017. Disponível em http://basenacionalcomum.mec.gov.br/images/BNCC_publicacao.pdf Acesso em 04 de abril de 2017.

CBC/SEE-MG. Conteúdos básicos comuns; História, ensinos fundamental e médio. Secretaria de Estado de Educação de Minas Gerais. Disponível em http://crv.educacao.mg.gov.br/sistema_crv/banco_objetos_crv/\%7B80A9F6A7-110D-42C2ACB1-A52372D19CB6\%7D LIVRO\%20DE\%20HISTORIA.pdf Acesso em 21 de março de 2011.

DAVIDOV, V. V. Tipos de generalización en la enseñanza. Habana: Editorial Pueblo y Educación, 1982.

1988.

La enseñanza escolar y el desarrollo psíquico. Moscú: Editorial Progreso,

DESGAGNÉ, Serge. O conceito de pesquisa colaborativa; a ideia de uma aproximação entre pesquisadores universitários e professores práticos. Revista Educação em Questão. Natal. Vol. 29, $\mathrm{n}^{\mathrm{o}}$ 15, p. 7-35, maio/agosto. 2007. Disponível em $<$ http://www.revistaeduquestao.educ.ufrn.br/pdfs/v29n15.pdf. $>$. Acesso em: 04 de ago. de 2011.

LIBÂNEO, José Carlos. O dualismo perverso da escola pública brasileira: escola do conhecimento para os ricos, escola do acolhimento social para os pobres. Educação e Pesquisa. São Paulo; v. 38, $\mathrm{n}^{\mathrm{o}}$ 1, p.13-28, 2012. Disponível em: <http://www.scielo.br/pdf/ep/v38n1/aop323.pdf $>$. Acesso em: 15 de fev. de 2013.

MELLO, Sueli Amaral. Ensinar e aprender a linguagem escrita na perspectiva históricocultural. Psicologia Política. Vol. 10, $\mathrm{n}^{0}$ 20, Dezembro de 2010. Disponível em: $<$ http://pepsic.bvsalud.org/pdf/rpp/v10n20/v10n20a11.pdf $>$. Acesso em: 18 de mar. de 2013.

OLIVEIRA, Sandra Regina Ferreira. O tempo, a criança e o ensino de história. In: ZAMBONI, Ernesta \& DE ROSSI, Vera Lúcia S (orgs.). Quanto tempo o tempo tem! Campinas; Ed. Alínea, 2003. pp. 145-172.

PIAGET, Jean. Psicologia da criança e ensino de história. In: PARRAT, S. e TRYPHON, A. (org.) e PIAGET, Jean. Sobre a pedagogia. São Paulo; Casa do Psicólogo, 1998. p. 8995.

A noção de tempo na criança. Rio de Janeiro; Civilização Brasileira, 2012. 
PIMENTA, Selma G. Pesquisa-ação crítico-colaborativa: construindo seu significado a partir de experiências com a formação docente. Educação e Pesquisa. São Paulo. v. 31, n. 3, p. 521-539, 2005. Disponível em <http://www.scielo.br/pdf/ep/v31n3/a13v31n3.pdf $>$. Acesso em: 03 de mar. de 2010.

PINO, Angel. As marcas do humano: às origens da constituição cultural da criança na perspectiva de Lev. S. Vigotski. São Paulo; Cortez, 2005.

SFORNI, Marta S. F. Interação entre didática e teoria histórico-cultural. Educação e Realidade. Porto Alegre. v. 40, n. 2, p. 375-397. 2015. Disponível em: $<$ http://www.scielo.br/pdf/edreal/v40n2/2175-6236-edreal-45965.pdf $>$. Acesso em: 10 de abr. de 2016.

SILVA, Aracy Lopes. Mito, razão, história e sociedade: inter-relações nos universos socioculturais. In: SILVA, Aracy L e GRUPIONI, Donizete Benzi (Orgs.). A temática indígena na escola: novos subsídios para professores de $1^{\circ}$ e $2^{\circ}$ graus. Brasília, MEC/MARI/UNESCO, 1995. pp. 317-335.

A construção do pensamento e da linguagem. São Paulo: Martins Fontes, 2001.

Quarta aula: a questão do meio na pedologia. Psicologia USP. São Paulo; V. 21, n 4; 2010. Disponível em: <http://www.scielo.br/pdf/pusp/v21n4/v21n4a03.pdf >. Acesso em: 03 de fev. de 2011.

ZEICHNER, Kenneth M. Para além da divisão entre professor-pesquisador e pesquisador acadêmico. In: GERALDI, Corinta G., FIORENTINI, Dario e PEREIRA, Elisabete M. A. (orgs). Cartografias do trabalho docente. Campinas; Mercado de Letras, 1998.

\section{Olavo Pereira Soares}

Graduação em História Licenciatura pela UNESP/Assis, com Mestrado e Doutorado em Educação pela USP - Universidade de São Paulo. Pesquisa sobre ensino de história, didática, currículo e formação de professores. Atua nos cursos de graduação em História e Pedagogia da UNIFAL/MG e no PPGE - Programa de Pós-graduação em Educação da UNIFAL/MG. 